\title{
HIGH STRENGTH LIGHTWEIGHT STRAIN-HARDENING CEMENTITIOUS COMPOSITE INCORPORATING CENOSPHERE
}

\author{
ZHITAO CHEN ${ }^{*}$, JUNXIA LI ${ }^{\dagger}$ AND EN-HUA YANG ${ }^{\dagger \dagger}$ \\ Nanyang Technological University \\ Singapore \\ e-mail: ztchen@ ntu.edu.sg \\ ${ }^{\dagger}$ Nanyang Technological University \\ Singapore \\ e-mail: jli019@e.ntu.edu.sg \\ † Nanyang Technological University \\ Singapore \\ e-mail: ehyang@ntu.edu.sg
}

Key words: Lightweight, High Strength, Engineered Cementitious Composite, Cenosphere

\begin{abstract}
High strength lightweight concrete was originally designed for potential structural applications. However, the brittle nature and higher permeability became the main drawbacks for further broad application. In this case, it is imperative to develop a special type of high strength strain hardening lightweight cementitious composite, offering higher ductility, lower permeability and considerable weight saving. Engineered cementitious composite (ECC) is a class of high performance fiber reinforced composite characterized by strain hardening behavior and tight crack width. In this study, the low density of below $1500 \mathrm{~kg} / \mathrm{m}^{3}$ was achieve by introduce lightweight fine aggregates of cenosphere obtained from coal-fired power station to fully replace silica sand generally used in ECC preparation. Binary and ternary binder systems (cement, silica fume and slag) were employed to tailor the matrix properties for obtaining higher strength of more than 50 MPa and lower permeability. Polymeric fibers having a good compatibility with matrix were used to implement strain hardening behavior and higher ductility. The permeability and thermal conductivity tests were conducted to evaluate the applicable performance of resulting lightweight cementitious composite. The correlation between mechanical, physical and thermal properties was build up to reveal the effect of cenosphere on the performances of high strength lightweight strain hardening cementitious composite. The single fiber pull out test and matrix fracture toughness test were conducted to reveal the micromechanical mechanism of strain hardening behavior of high strength lightweight composites.
\end{abstract}

\section{INTRODUCTION}

Lightweight concrete is widely used in construction of structure requiring high strength/weight ratio such as high-rise building and long-span structures [1, 2]. The use of lightweight concrete in constructions can offer many advantages such as weight saving, thermal insulation, saving in steel reinforcement and reduction in overall cost, etc. To achieve lower density, the lightweight concrete is traditionally made by using lightweight aggregate with porous structure or introducing foam into matrix [3-5]. However, its mechanical properties are considerably lower than normal concrete as the lightweight 
aggregate is usually weaker than cement matrix and normal aggregates. In addition, the lightweight concrete typically exhibits more brittle behavior than normal concrete with similar compressive strength. Based on above drawbacks of lightweight concrete, the structural use especially load bearing members of lightweight concrete is limited. In order to expand the structural application, it is necessary to improve the mechanical properties of lightweight concrete in terms of adequate strength, acceptable ductility or a combination of both.

Engineered cementitious composite (ECC) is a kind of high performance fiber reinforced cement based composite characterized by high tensile ductility with moderate fraction of fiber (typically 2\%) and comparable compressive strength (typically 40-70MPa). The density of typical ECC M45 is around $2050 \mathrm{~kg} / \mathrm{m}^{3}$, which is lower than normal concrete with density of about $2400 \mathrm{~kg} / \mathrm{m}^{3}$. But typical ECC still cannot meet the specification of lightweight concrete with regard to the density of $1850 \mathrm{~kg} / \mathrm{m}^{3}$. In the past, several researches have reported the lightweight ECC [6, 7]. Wand and Li [6] developed fifteen lightweight ECC firstly by incorporating three kinds of lightweight aggregates and using air entrainment admixture to achieve low density range from $930 \mathrm{~kg} / \mathrm{m}^{3}$ to $1800 \mathrm{~kg} / \mathrm{m}^{3}$. Among these mix designs, the lightweight ECC using hollow glass bubbles can achieve the tensile strain capacity of 3-4\%. The compressive strength of such lightweight ECC with density higher than $1450 \mathrm{~kg} / \mathrm{m}^{3}$ is around $40 \mathrm{MPa}$. Huang et al. [7] also investigated the green lightweight ECC incorporating large amount of lightweight industrial waste materials (fly ash cenosphere and iron ore tailings) to reduce the environmental impact of resulting materials. In that study, the lightweight ECC exhibits density of $1649-1820 \mathrm{~kg} / \mathrm{m}^{3}$, tensile strain capacity of 3-4\% and compressive strength 25 47.6 MPa. In the previous studies, the already developed lightweight ECC exhibits good mechanical and physical properties. However, the compressive strength is still lower than 50 $\mathrm{MPa}$ and the density must be higher than 1500 $\mathrm{kg} / \mathrm{m}^{3}$ when the strength achieves $40 \mathrm{MPa}$.
Wang et al. [8] developed a series of fiber reinforced ultra lightweight cement composites by using cenosphere and higher amount of binders. The density can achieve below 1500 $\mathrm{kg} / \mathrm{m}^{3}$ and the compressive strength reach over $60 \mathrm{MPa}$. However, although the flexural properties are enhanced by incorporating low content of fibers, the ductility of resulting ultra lightweight cement composites cannot be compared with ECC.

In order to further improve the compressive strength and reduce the density of ECC with acceptable ductility, the ECC design theory and ultra lightweight cement composite design philosophy are combined together in this study to develop a new type ultra lightweight ECC. In this study, binary and ternary binder systems are employed to tailor a strong cement matrix. The higher dosage of cenosphere is used to completely replace fine silica sand as only lightweight aggregate for achieving low density. The moderate volume fraction of PVA fiber is added to implement the high ductility. The mechanical properties in terms of compressive strength and tensile ductility as well as the physical properties in terms of dry density, thermal conductivity and water absorption are determined to evaluated the performances of resulting high strength lightweight ECC.

\section{EXPERIMENTAL PROGRAM}

The raw materials used for preparing high strength lightweight engineered cementitious composite (HSL-ECC) include cement, silica fume, GGBS, cenosphere, PVA fiber, water and superplasticizer. To achieve higher strength, the CEM I $52.5 \mathrm{~N}$ Portland cement and silica fume with dosage of $8 \%$ by mass of binders are used in all mixutres. The GGBS is used to replace $20 \%-60 \%$ cement for improving the properties of ECC and reducing the amount of cement. The cenosphere used in all mixtures has a bulk density of approximately $400 \mathrm{~kg} / \mathrm{m}^{3}$. The particle size of most of the cenosphere ranges from $45 \mu \mathrm{m}$ to $300 \mu \mathrm{m}$. Figure 1 shows the SEM image of the cenosphere with sphere surface and hollow structure. The chemical composition and 
physical properties of cenosphere is shown in table 1 .

Table 1: Che mical co mposition and physical properties of cenosphere

\begin{tabular}{|c|c|c|}
\hline \multirow{6}{*}{$\begin{array}{c}\text { Chemical } \\
\text { compos ition, } \%\end{array}$} & $\mathrm{SiO}_{2}$ & 58 \\
\hline & $\mathrm{Al}_{2} \mathrm{O}_{3}$ & 35 \\
\hline & $\mathrm{Fe}_{2} \mathrm{O}_{3}$ & 2.0 \\
\hline & $\mathrm{CaO}$ & 1.1 \\
\hline & $\mathrm{TiO}_{2}$ & 1.05 \\
\hline & LOI & 0.8 \\
\hline \multirow{5}{*}{$\begin{array}{l}\text { Physical } \\
\text { properties }\end{array}$} & $\begin{array}{l}\text { Bulk density, } \\
\text { g/cc }\end{array}$ & 0.4 \\
\hline & True density, g/cc & 0.85 \\
\hline & $\begin{array}{c}\text { Thermal } \\
\text { conductivity, } \\
\text { W/mK }\end{array}$ & 0.08 \\
\hline & Strength, psi & 2500 \\
\hline & Melting point, ${ }^{\circ} \mathrm{C}$ & 1600 \\
\hline
\end{tabular}
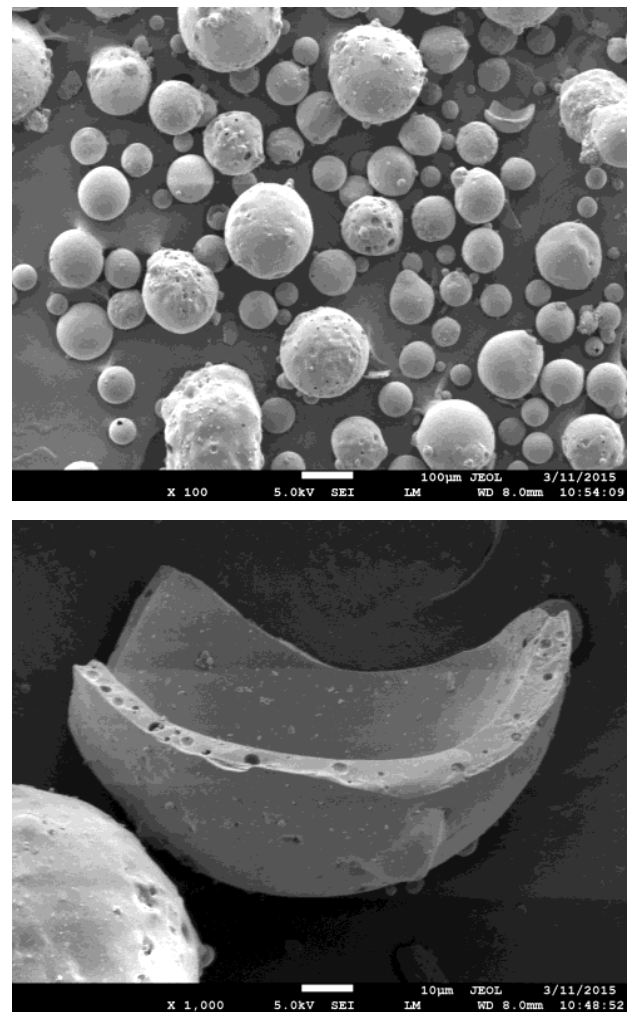

Figure 1: SEM image of hollow cenos phere particles .

PVA REC15 fiber, which is specially developed for ECC materials, is incorporated in all mixtures to improve ductility of high strength lightweight ECC. The surface of the PVA fibers is treated by coating with $1.2 \%$ of oil by weight. The physical and geometrical properties of PVA fiber is shown in table 2.

Table 2: Physical and geometrical properties of PVA fiber

\begin{tabular}{cc}
\hline Length $(\mathrm{mm})$ & 12 \\
\hline Diameter $(\mu \mathrm{m})$ & $39-44$ \\
\hline Young's modulus $(\mathrm{GPa})$ & 42 \\
\hline Elongation $(\%)$ & 7 \\
\hline Tensile strength $(\mathrm{MPa})$ & 1,600 \\
\hline Density $\left(\mathrm{g} / \mathrm{cm}^{3}\right)$ & 1.3 \\
\hline
\end{tabular}

Four mixtures are prepared in this study to investigate the properties of resulting high strength lightweight ECC (HSL-ECC). The mix proportion is given in table 3 . The water binder ratio is 0.27 for all mixtures. The dosage of silica fume is fixed at $8 \%$ of total binder materials. The GGBS is used to replace cement from $20 \%$ to $60 \%$. The fraction of cenosphere is approximate $42 \%$ of binders by weight. The volume fraction of PVA fiber is fixed at $2 \%$. The dosage of superplasticizer is adjusted according to the rheological properties of fresh paste for homogenous fiber dispersion. The mixture without GGBS substitution is used as control mix denoted as C. The mixtures with $20 \%, 40 \%$ and $60 \%$ GGBS replacement level are denoted as G1, $\mathrm{G} 2$ and $\mathrm{G} 3$, respectively.

Table 3: Mix proportion of HSL-ECC, $\mathrm{kg} / \mathrm{m}^{3}$

\begin{tabular}{ccccc}
\hline Mix ID & C & G1 & G2 & G3 \\
\hline Cement & 828 & 658 & 490 & 324 \\
\hline GGBS & 0 & 164 & 327 & 487 \\
\hline Silica fume & 72 & 71 & 71 & 71 \\
\hline Cenosphere & 378 & 375 & 373 & 370 \\
\hline Water & 243 & 241 & 240 & 238 \\
\hline Superplasticizer & 7 & 5 & 4 & 4 \\
\hline Fiber & 26 & 26 & 26 & 26 \\
\hline
\end{tabular}

The mixtures are mixed followed by a typical ECC mixing procedure described by Chen [9]. For each mix, Three $50 \mathrm{~mm}$ cubes for compressive strength tests, three $50 \mathrm{~mm}$ cubes for determine dry density and thermal conductivity and after that for determination of rate of water absorption and five dogbone 
specimens for direct tension tests are prepared. In addition, the specimens without fiber for matrix toughness tests and specimens for single fiber pullout tests are also prepared. The geometry of specimens and preparing process are described in Ref. [10]. All specimens are demolded after 24 hours and cured in a sealed plastic bag for 28 days until to various tests.

The compressive strength tests are conducted by using hydraulic compression machine at a loading rate of $100 \mathrm{kN} / \mathrm{min}$. To verify the strain-hardening behavior of ECC, the direct tensile test was conducted by using electronic universal testing machine with $50 \mathrm{kN}$ capacity. Two LVTD were used to monitor the deformation of the sample with a gage length of $100 \mathrm{~mm}$. The test was carried out under displacement control at a rate of $0.2 \mathrm{~mm} / \mathrm{min}$. The test methods for single fiber pull out and matrix toughness are indicated in Ref. [10]. The dry density of ECC is simply determined by using weight of dry specimens divided by volume of specimen $\left(125 \mathrm{~cm}^{3}\right)$. The rate of water absorption is determined according to ASTM C 1585 with a small change on shape of specimen. The cubic specimen is used in this study instead of cylinder in the standard. The thermal conductivity is determined by using hot disk thermal constant analyzer.

\section{RESULTS AND DISCUSSION}

\subsection{Mechanical properties of HSL-ECC}

Figure 2 shows the 28 days compressive strength of HSL-ECC. As can be seen from Figure 2, the compressive strength of control mix can reach more than $55 \mathrm{MPa}$ at 28 days. In comparison with control mixture, the mixture G1 has a marginal increase in compressive strength. However, the compressive strength has a slightly decrease when the replacement level of GGBS is up to $40 \%$. The marginal increase of G1 incorporating mixtures in comparison with control mixture is possibly attributed to the effect of particle packing. The addition of GGBS can adjust the cementitioius materials to ternary binder system, which can further improve the particle size distribution in comparison with binary binder system. However, when the replacement level is higher than $40 \%$, the decrease of amount of cement may result in the decrease of strength of primary product of hydration.

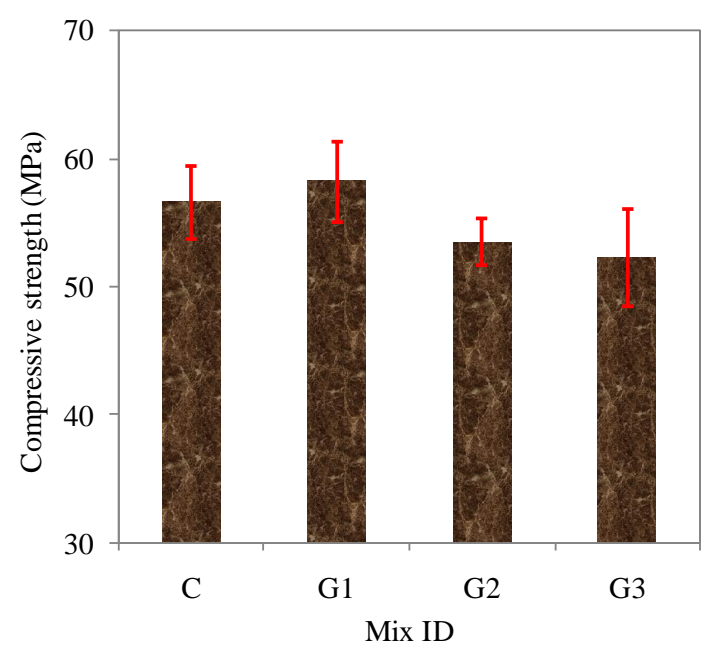

Figure 2: Compressive strength of HSL-ECC at 28 days

Figure 3 shows the typical uniaxial tensile stress-strain curves of HSL-ECC. Under uniaxial tensile loading, all HSL-ECC mixtures exhibit strain hardening behavior and multiple cracking. The ultimate tensile strain of control mixture can reach approximate $1.5 \%$. The mixtures of G1, G2 and G3 show a similar ultimate tensile strain of $1 \%$, which is slightly lower than control mixture. In addition, the ultimate tensile stress of control mixture can reach around $5 \mathrm{MPa}$, which is higher than GGBS incorporating mixtures. Based on the direct tension results, incorporating GGBS in mix design of HSLECC is not optimal tailoring solution for obtaining good tensile ductiliy and mechnical properties. However, the properties of resulting HSL-ECC are acceptable from the preliminary results. 


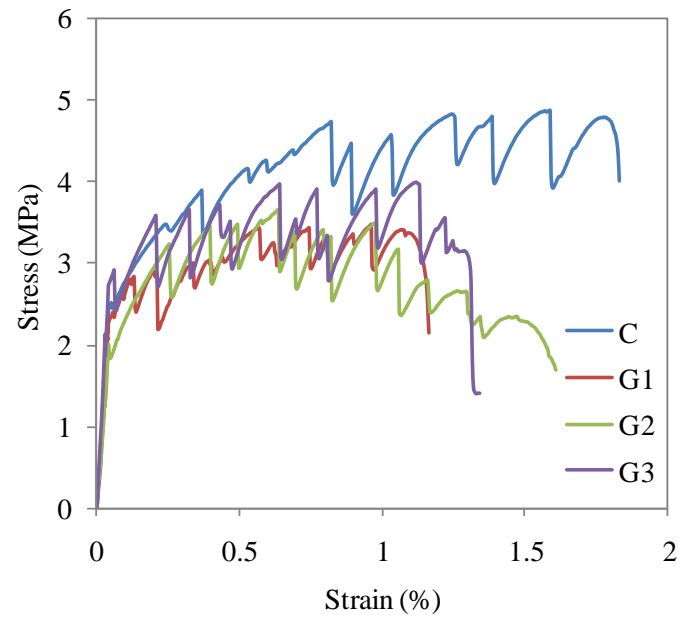

Figure 3: Typical tensile stress-strain curves of HSLECC

According to the micromechanics base design theory of ECC, both strength criteria and energy criteria must be satisfied to obtain multiple cracking behavior [11]. Based on this theory, the higher complementary energy $J_{b}{ }^{\prime}$ to crack tip toughness $J_{\text {tip }}$ ratio is favorable for obtaining robust tensile ductility. Figure 4 shows the matrix toughness of HSL-ECC and Figure 5 shows the main micromechanical parameters related to $J_{b}{ }^{\prime}$ of chemical bond strength $G_{d}$ and frictional bond strength of $\tau_{0}$. The increasing of dosage of GGBS can decrease the matrix toughness as shown in Figure 4. When the dosage of GGBS is lower than $40 \%$, the addition of GGBS can increase the matrix toughness in comparison with control mixture. This is due to the GGBS particles are activated by calcium hydroxide from hydration of cement, which can lead to decrease of porosity of matrix resulting in enhanced strength and toughness of matrix. But the amount of calcium hydroxide only from hydration of cement is not enough to activate all GGBS particles when its dosage exceeds $40 \%$. Matrix toughness of G2 shows a similar value to control mixture and G3 shows a slight decrease in matrix toughness. Figure 5 shows the micromechanical parameters obtained from single fiber pullout tests. The chemical bond strength $G_{d}$ is primarily determined by the chemical structures between fiber surface and cement matrix. As seen in Figure 5a, the chemical bond $G_{d}$ in G1 shows an increase and significant decrease in G2 and
G3 in comparison with control mixture. This is principally due to the dilute effect of GGBS on cement. PVA fiber is a kind of hydrophilic fiber having strong chemical bond with cement matrix. The increasing of replacement ratio of cement by GGBS has a dilute effect on cement in ternary binders system, which can reduce the valid chemical bond between PVA fiber surface and cement matrix resulting in decreasing of chemical bond. In this study, the frictional bond $\tau_{0}$ in GGBS incorporating mixtures shows a decreasing in comparison with control mixture. This finding is contradicted to the previous research by $\mathrm{Kim}$ [10]. On the one hand, the water binder ratio of 0.27 in this study is lower than the former of $0.38-0.48$, the interfacial zone between fiber and cement matrix should be similar in all mixes. In addition, the silica fume can further decrease the porosity of ITZ, which can weaken the effect of porosity of ITZ on $\tau_{0}$. Certainly, the phenomenon should be confirmed in further study.

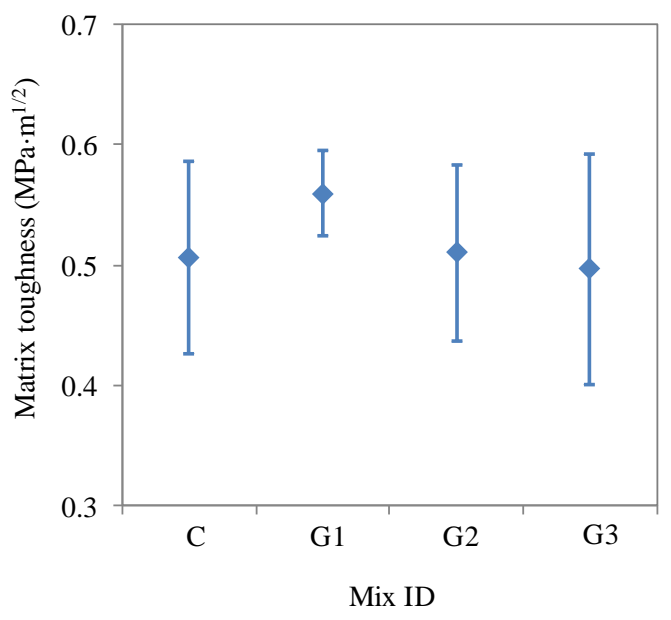

Figure 4: Matrix toughness of HSL-ECC

\subsection{Physical properties of HSL-ECC}

The density and thermal conductivity are two most important physical indexes for evaluating the properties of lightweight cement based materials. Figure 6 shows the dry density of HSL-ECC at 28 days. The dry density is measured after 28 days sealed curing and drying for 7 days at $90{ }^{\circ} \mathrm{C}$ to constant weight. As seen in Figure 6, the dry density of HSL-ECC ranges from $1240 \mathrm{~kg} / \mathrm{m}^{3}$ to 1270 
$\mathrm{kg} / \mathrm{m}^{3}$. The addition of GGBS shows a marginally decrease in the density of HSLECC in comparison with control mixture. Due to the density of HSL-ECC in this study is mainly determined by the amount of cenosphere, there is no significant difference in density resulting from a fixed dosage of cenosphere. The decrease of density in GGBS groups mainly due to the density of GGBS is lower than that of cement.
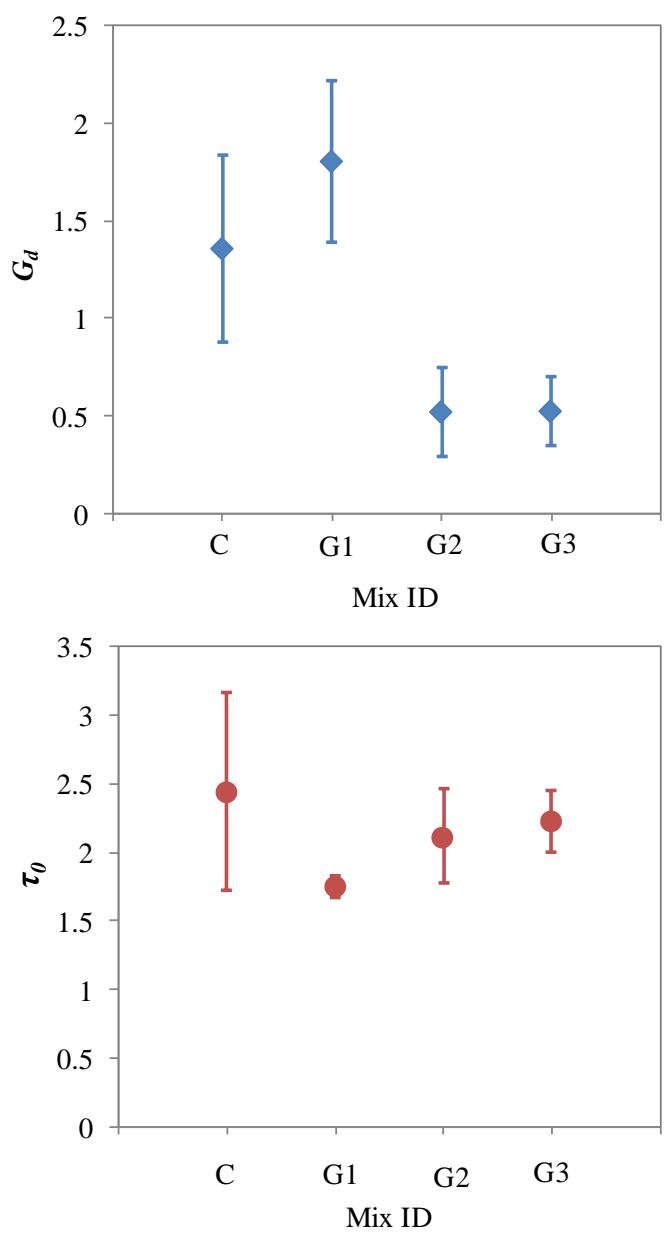

Figure 5: Chemical bond strength $G_{d}$ and frictional bond strength $\tau_{0}$ of HSL-ECC

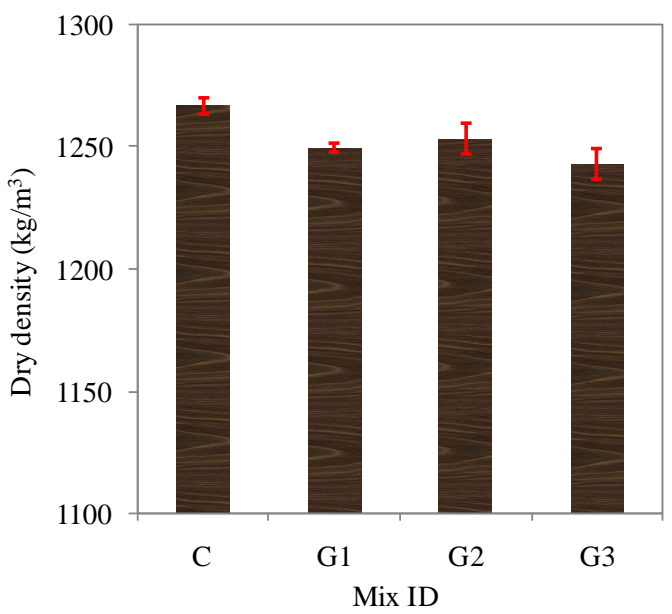

Figure 6: Dry density of HSL-ECC

Figure 7 shows the thermal conductivity of HSL-ECC. The thermal conductivity of HSLECC ranges from $0.39 \mathrm{w} / \mathrm{mK}$ to $0.45 \mathrm{w} / \mathrm{mK}$, which is much lower than normal concrete. The low thermal conductivity of HSL-ECC is due to addition of cenosphere with low thermal conductivity of $0.08 \mathrm{w} / \mathrm{mK}$. In addition, replacing cement by GGBS shows a small variation on thermal conductivity of HSL-ECC. On the one hand, the thermal conductivity of GGBS is different from cement. On the other hand, the addition of GGBS can improve the particle packing of binder system and the rheological behavior to help escaping entrapped air. The decreasing of porosity can increase the thermal conductivity.

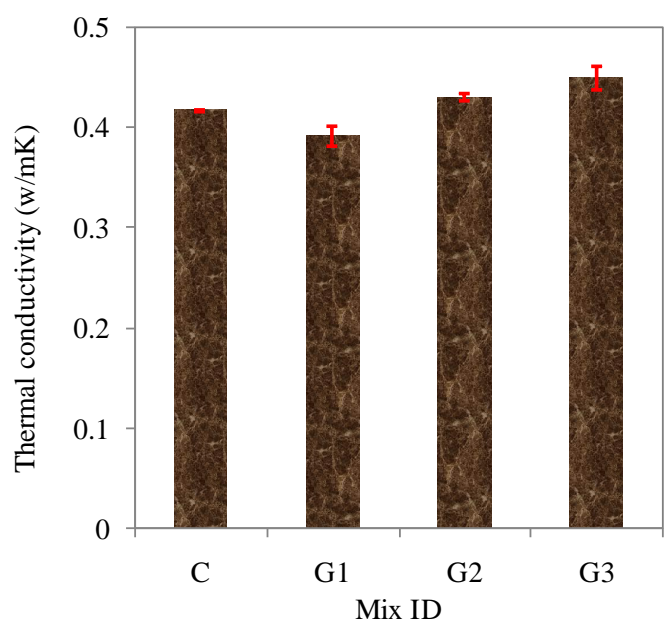

Figure 7: Thermal conductivity of HSL-ECC

Figure 8 shows the rate of water absorption of HSL-ECC. The y axis represents the change 
in mass of water divided by the product of the cross-sectional area of the test specimen and the density of water. The $\mathrm{x}$ axis represents the square root of time in seconds. As seen from the curves, the rate of water absorption of HSL-ECC shows a similar trend. The curve can be divided into two parts: initial absorption and secondary absorption. The initial rate of absorption is defined as the slope of the curve obtained using linear regression analysis using the points from $1 \mathrm{~min}$ to $6 \mathrm{~h}$. The secondary rate of absorption is defined as the slope of the curve obtained using linear regression analysis using the points from $1 \mathrm{~d}$ to $7 \mathrm{~d}$. in control mixture In this study, the addition of $20 \%$ GGBS in HSL-ECC shows an lower rate of water absorption. The reason is the same as the discussion above due to the optimal particle packing and activation of GGBS to reduce the porosity of cement matrix. In addition, the rate of water absorption of all HSL-ECC is much lower than normal lightweight concrete. On the one hand, the HSL-ECC is designed by incorporating binary and ternary binders system with lower water binder ratio of 0.27 . The capillary pores of resulting HSL-ECC are greatly reduced. Furthermore, the cenosphere has a strong shell structure and the water is not easy to penetrate inside. Both above advantages give a good water absorption resistance to the HSL-ECC.

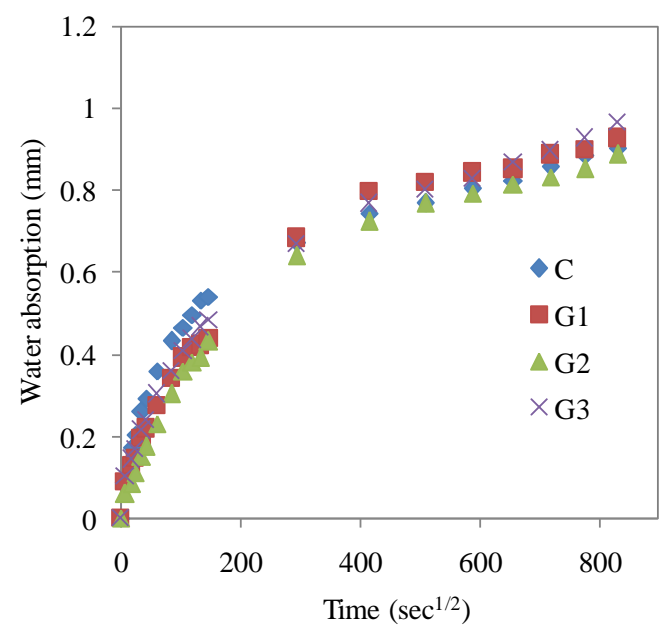

Figure 8: Rate of water absorption of HSL-ECC

\section{CONCLUSIONS}

In this study, the high strength lightweight ECC (HSL-ECC) with density lower 1300 $\mathrm{kg} / \mathrm{m}^{3}$ is developed through binders system design and incorporating higher dosage of cenosphere. The resulting HSL-ECC exhibits an acceptable tensile strain capacity of over $1 \%$ and higher 28 days compressive strength of more than $50 \mathrm{MPa}$. In addition, replacing normal fine aggregates with cenosphere not only significantly reduce the weight of materials, but also obtain lower thermal conductivity of below $0.5 \mathrm{w} / \mathrm{mK}$ and lower rate of water absorption. Base on the preliminary results, the tensile strain capacity of HSL-ECC has not reach the level of ultra high ductility. It is necessary to tailor the matrix by incorporating fly ash for obtaining higher tensile strain capacity and reveal the mechanism according to micromechanical model.

\section{REFERENCES}

[1] Chandra, S. and Berntsson, L. 2002. Lightweight aggregate concrete: science, technology and applications. William Andrew Publishing, New York.

[2] ACI Committee 231. 1987. Guide for structural lightweight aggregate concrete.

[3] Lotfy, A., Hossain,K. M. A. and Lachemi, M. 2016. Durability properties of lightweight self-consolidating concrete developed with three types of aggregates. Construction and Building Materials 106:43-54.

[4] Jiang, J., Lu, Z., Niu, Y., Li, J. and Zhang, Y. 2016. Study on the preparation and properties of high-porosity foamed concretes based on ordinary Portland cement. Materials and Design 92: 949959.

[5] Amran, Y. H. M., Farzadnia, N. and Ali, A. A. A. 2015. Properties and applications of foamed concrete; a review. Construction and Building Materials 101: 990-1005.

[6] Wang, S. and Li, V.C. 2003. Lightweight engineered cementitious composites (ECC). Proceedings of 4th International RILEM workshop on high performance 
fiber reinforced cement composites (HPFRCC 4); pp. 379-390.

[7] Huang, X., Ranade, R., Zhang, Q., Ni, W. and Li, V.C. 2013. Mechanical and thermal properties of green lightweight engineered cementitious composites. Construction and Building Materials 48: 954-960.

[8] Wang, J., Chia, K., Liew, J. R. and Zhang, M. H. 2013. Flexural performance of fiber-reinforced ultra lightweight cement composites with low fiber content. Cement and Concrete Composites 43: 3947.

[9] Chen, Z. T., Yang, E. H., Yang, Y. Z. and Yao, Y. 2014. Latex-modified engineered cementitious composites (L-ECC). Journal of Advanced Concrete and Technology 12: 510-519.

[10] Kim, J. K., Kim, J. S., Ha, G. J. and Kim, Y. Y. 2007. Tensile and fiber dispersion performance of ECC (engineered cementitious composites) produced with ground granulated blast furnace slag. Cement and Concrete Research 37: 10961105.

[11] Li, V.C. 2012. Tailoring ECC for special attributes: a review. International Journal of Concrete Structures and Materials 6: 135-144. 